\title{
Lung ultrasound findings in patients with COVID-19 pneumonia
}

\author{
Changyang Xing ${ }^{1 \dagger}$, Qiaoying $\mathrm{Li}^{1+}$, Hong Dü ${ }^{2 \dagger}$, Wenzhen Kang ${ }^{2}$, Jianqi Lian ${ }^{2^{*}}$ and Lijun Yuan ${ }^{{ }^{*}}$
}

Keywords: COVID-19, Lung ultrasound, SARS-CoV-2, Deep vein thrombosis

Since December 2019, the outbreak of pneumonia caused by a new coronavirus [1], which was later identified as coronavirus disease 2019 (COVID19), has infected more than 410,000 patients globally according to the situation report of World Health Organization. Lung ultrasound is an important tool for the diagnosis and follow-up of pneumonia in neonates, children, and adults [2-4]. Recent CT reports demonstrated that most of the lesions were distributed peripherally in the lung, which facilitates detection by lung ultrasound $[5,6]$. In this study, we characterize the lung ultrasound findings COVID-19 pneumonia, and study the relationship between the ultrasound findings and clinical severity and the time-course of disease progress. Bedside lung ultrasound was performed to detect B-lines, lung consolidation, and pleural line abnormalities at 5 areas in each lung. Vascular ultrasound was also performed to detect potential deep vein thrombosis.

A total of 20 patients of COVID-19 pneumonia (12 males and 8 females) were categorized as 4 moderate, 5 severe, and 11 critical cases according to the current diagnosis and treatment program. All patients showed abnormal lung ultrasound findings, including $100 \%$ (20) pleural line abnormalities, 100\% (20) B-lines, and 50\% (10) consolidation. Most of the moderate and severe cases could show both

\footnotetext{
* Correspondence: yuanlj@fmmu.edu.cn; lianjq@fmmu.edu.cn

${ }^{+}$Changyang Xing, Qiaoying Li and Hong Du contributed equally to this work.

'Department of Ultrasound Diagnostics, Tangdu Hospital, Fourth Military Medical University, Xi'an 710038, China

${ }^{2}$ Department of Infectious Diseases, Tangdu Hospital, Fourth Military Medical University, Xi'an 710038, Shaanxi, China
}

separated B-lines and confluent B-lines during admission. All critical patients showed confluent Blines, and $18 \%$ (2) of them had compact B-lines. Bilateral involvement was observed in all patients. The predominate involved areas in moderate patients were on the back, i.e., the interscapular and infrascapular areas. For severe and critical patients, all 5 areas could be involved. Consolidations were not detected in moderate cases, and distributed mainly on the posterior areas in severe and critical cases. Pleural effusion (18\%, 2 cases), pericardial effusion (9\%, 1 case), and deep vein thrombosis (64\%, 5 cases) were only found in critical patients. (Table 1).

A total of 36 ultrasound examinations were categorized to four groups based on the time interval between onset of symptoms and ultrasound examinations (1st to 4th week). All of the examinations showed abnormal lung ultrasound findings, including $100 \%$ (36) pleural line abnormalities, $100 \%$ (36) B-lines, and $64 \%$ (23) consolidation. The separate B-lines were found more than half of the examinations after the 2nd week. The majority of examinations during the 2nd and 3rd weeks showed confluent B-lines. The involvement of anterior areas with $\mathrm{B}$-lines decreased along with the infected time course. The lateral and back areas were always involved in all stages for B-lines. Consolidations were found in more than half examinations after the 1st week. Most of consolidation lesions confined within unilateral lung except at the 2nd week. The anterior and lateral areas were not involved of consolidations during 1st and 4th week. Consolidations were 
Table 1 Lung ultrasound findings in different clinical severity

\begin{tabular}{|c|c|c|c|}
\hline & $\begin{array}{l}\text { Moderate } \\
(n=4)\end{array}$ & $\begin{array}{l}\text { Severe } \\
(n=5)\end{array}$ & $\begin{array}{l}\text { Critical } \\
(n=11)\end{array}$ \\
\hline Pleural line abnormalities & $100 \%(4)$ & $100 \%(5)$ & $100 \%(11)$ \\
\hline B-lines & $100 \%(4)$ & $100 \%(5)$ & $100 \%(11)$ \\
\hline Separated B-lines & $75 \%(3)$ & $80 \%(4)$ & $36 \%(4)$ \\
\hline Confluent B-lines & $75 \%(3)$ & $80 \%(4)$ & $100 \%(11)$ \\
\hline Compact B-lines & 0 & 0 & $18 \%(2)$ \\
\hline Bilateral involvement & $100 \%(4)$ & $100 \%(5)$ & $100 \%(11)$ \\
\hline Anterior upper area & $25 \%(1)$ & $100 \%(5)$ & $100 \%(11)$ \\
\hline Anterior lower area & $50 \%(2)$ & $100 \%(5)$ & $100 \%(11)$ \\
\hline Lateral area & $75 \%(3)$ & $100 \%(5)$ & $100 \%(11)$ \\
\hline Interscapular area & $100 \%(4)$ & $100 \%(5)$ & $100 \%(11)$ \\
\hline Infrascapular area & $100 \%(4)$ & $100 \%(5)$ & $100 \%(11)$ \\
\hline Consolidation & 0 & $60 \%(3)$ & $64 \%(7)$ \\
\hline Bilateral involvement & 0 & $40 \%(2)$ & $54 \%(6)$ \\
\hline Anterior upper area & 0 & 0 & $18 \%(2)$ \\
\hline Anterior lower area & 0 & 0 & $18 \%(2)$ \\
\hline Lateral area & 0 & $20 \%(1)$ & $18 \%(2)$ \\
\hline Interscapular area & 0 & $20 \%(1)$ & $64 \%(7)$ \\
\hline Infrascapular area & 0 & $60 \%(3)$ & $64 \%(7)$ \\
\hline Pleural effusion & 0 & 0 & $18 \%(2)$ \\
\hline Pericardial effusion & 0 & 0 & $9 \%(1)$ \\
\hline Deep vein thrombosis & 0 & 0 & $64 \%(7)$ \\
\hline
\end{tabular}

Data are presented as percentages (number of cases)

always found in the interscapular and infrascapular areas. Pleural effusion was observed across all stages, but only in a few examinations. The deep vein thrombosis can be found since the 1 st week and most prevalent at the 4 th week $(62.5 \%, 5$ cases). (Table 2).

In summary, abnormal lung ultrasound findings, mainly B-lines, consolidation and pleural line abnormalities, were found in patients infected with COVID-19 pneumonia. Bilateral involvement was always observed with predominant distribution in the posterior part of the lungs. The composition of different density of B-lines and areas of consolidation showed parallel changes with the clinical severity. The extent of disease demonstrated by ultrasound findings seemed reaching the peak at the 2nd week and recovering gradually thereafter. Collectively, lung ultrasound could serve as a valuable tool for the detection and follow-up of lung lesions in COVID-19 pneumonia and also provide supplemental imaging information for current recommended radiological examination, with the advantages of radiation-free, flexibility, and cost effective.
Table 2 Lung ultrasound findings in different infection stage

\begin{tabular}{lllll}
\hline & $\begin{array}{l}\text { 1st week } \\
(\boldsymbol{n}=\mathbf{4})\end{array}$ & $\begin{array}{l}\text { 2nd week } \\
(\boldsymbol{n}=\mathbf{1 1})\end{array}$ & $\begin{array}{l}\text { 3rd week } \\
(\boldsymbol{n}=\mathbf{1 3})\end{array}$ & $\begin{array}{l}\text { 4th week } \\
(\boldsymbol{n}=\mathbf{8})\end{array}$ \\
\hline Clinical severity (\%) & & & & \\
Moderate & 0 & $18 \%(2)$ & $15 \%(2)$ & $12.5 \%(1)$ \\
Severe & $25 \%(1)$ & $18 \%(2)$ & $23 \%(3)$ & $25 \%(2)$ \\
Critical & $75 \%(3)$ & $64 \%(7)$ & $62 \%(8)$ & $62.5 \%(5)$ \\
Pleural line & $100 \%(4)$ & $100 \%(11)$ & $100 \%(13)$ & $100 \%(8)$ \\
abnormalities & & & & \\
B-lines & $100 \%(4)$ & $100 \%(11)$ & $100 \%(13)$ & $100 \%(8)$ \\
Separated B-lines & $50 \%(2)$ & $46 \%(5)$ & $69 \%(9)$ & $75 \%(6)$ \\
Confluent B-lines & $75 \%(3)$ & $91 \%(10)$ & $85 \%(11)$ & $75 \%(6)$ \\
Compact B-lines & $25 \%(1)$ & $18 \%(2)$ & $15 \%(2)$ & 0 \\
Bilateral involvement & $100 \%(4)$ & $100 \%(11)$ & $100 \%(13)$ & $87.5 \%(7)$ \\
Anterior upper area & $100 \%(4)$ & $91 \%(10)$ & $85 \%(11)$ & $87.5 \%(7)$ \\
Anterior lower area & $100 \%(4)$ & $91 \%(10)$ & $77 \%(10)$ & $75 \%(6)$ \\
Lateral area & $100 \%(4)$ & $100 \%(11)$ & $100 \%(13)$ & $100 \%(8)$ \\
Interscapular area & $100 \%(4)$ & $100 \%(11)$ & $100 \%(13)$ & $87.5 \%(7)$ \\
Infrascapular area & $100 \%(4)$ & $100 \%(11)$ & $100 \%(13)$ & $100 \%(8)$ \\
Consolidation & $50 \%(2)$ & $55 \%(6)$ & $77 \%(10)$ & $62.5 \%(5)$ \\
Bilateral involvement & $25 \%(1)$ & $55 \%(6)$ & $36 \%(4)$ & $25 \%(2)$ \\
Anterior upper area & 0 & $9 \%(1)$ & 0 & 0 \\
Anterior lower area & 0 & $9 \%(1)$ & $8 \%(1)$ & 0 \\
Lateral area & 0 & $18 \%(2)$ & $8 \%(1)$ & 0 \\
Interscapular area & $50 \%(2)$ & $55 \%(6)$ & $54 \%(7)$ & $62.5 \%(5)$ \\
Infrascapular area & $25 \%(1)$ & $55 \%(6)$ & $77 \%(10)$ & $62.5 \%(5)$ \\
Pleural effusion & $25 \%(1)$ & $9 \%(1)$ & $15 \%(2)$ & $12.5 \%(1)$ \\
Pericardial effusion & 0 & $9 \%(1)$ & $8 \%(1)$ & $12.5 \%(1)$ \\
\hline Deep vein thrombosis & $50 \%(2)$ & $46 \%(5)$ & $46 \%(6)$ & $62.5 \%(5)$ \\
\hline Data are presented as & & & &
\end{tabular}

Data are presented as percentages (number of cases)

Acknowledgements

Not applicable.

\section{Funding}

This study was supported by the Key Program of Digital Diagnosis and Therapy by Missions of the Ministry of Science and Technology (2017YFC0113800), National Science and Technology Major Project (2017ZX10204401-002-005), and Key Research and Development Program of Shaanxi Province (2020ZDXM-SF-003). Changyang Xing was supported by the grants from National Postdoctoral Program for Innovative Talents (BX20180377) and the Eyas Program of the Fourth Military Medical University.

\section{Availability of data and materials}

All data generated or analyzed during this study are included in this published article.

\section{Authors' contributions}

$\mathrm{LY}$ and $\mathrm{J}$ contributed to the study concept and design. CX, QL, HD, and WK contributed to the acquisition, analysis, or interpretation of data. CX contributed to the drafting the manuscript. QL, JL, LY, HD, and WK contributed to the critical revision of the manuscript. All contributed to the final approval of the manuscript. All agree to be accountable for all aspects of the work. Prof. LY and Prof. JL were the guarantors of the paper. The authors read and approved the final manuscript. 


\section{Ethics approval and consent to participate}

This study was approved by the ethics committee of Tangdu Hospital, Fourth Military Medical University. The requirement for informed patient consent was waived in light of the urgent need to collect clinical and imaging data.

\section{Consent for publication}

Consent for publication was obtained from every patient.

\section{Competing interests}

The authors declare that they have no competing interests.

\section{Publisher's Note}

Springer Nature remains neutral with regard to jurisdictional claims in published maps and institutional affiliations.

Received: 30 March 2020 Accepted: 6 April 2020

Published online: 28 April 2020

\section{References}

1. Huang C, Wang Y, Li X, Ren L, Zhao J, Hu Y, Zhang L, Fan G, Xu J, Gu X, et al. Clinical features of patients infected with 2019 novel coronavirus in Wuhan, China. Lancet. 2020;395(10223):497-506.

2. Liu J, Liu F, Liu Y, Wang HW, Feng ZC. Lung ultrasonography for the diagnosis of severe neonatal pneumonia. Chest. 2014;146(2):383-8.

3. Caiulo VA, Gargani L, Caiulo S, Fisicaro A, Moramarco F, Latini G, Picano E, Mele G. Lung ultrasound characteristics of community-acquired pneumonia in hospitalized children. Pediatr Pulmonol. 2013;48(3):280-7.

4. Reissig A, Copetti R, Mathis G, Mempel C, Schuler A, Zechner P, Aliberti S, Neumann R, Kroegel C, Hoyer H. Lung ultrasound in the diagnosis and follow-up of community-acquired pneumonia: a prospective, multicenter, diagnostic accuracy study. Chest. 2012;142(4):965-72.

5. Pan F, Ye T, Sun P, Gui S, Liang B, Li L, Zheng D, Wang J, Hesketh RL, Yang $L$, et al. Time course of lung changes on chest $C T$ during recovery from 2019 novel coronavirus (COVID-19) pneumonia. Radiology. 2020:200370. https://doi.org/10.1148/radiol.2020200370.

6. Shi H, Han X, Jiang N, Cao Y, Alwalid O, Gu J, Fan Y, Zheng C. Radiological findings from 81 patients with COVID-19 pneumonia in Wuhan, China: a descriptive study. Lancet Infect Dis. 2020;20(4):425-34.

- fast, convenient online submission

- thorough peer review by experienced researchers in your field

- rapid publication on acceptance

- support for research data, including large and complex data types

- gold Open Access which fosters wider collaboration and increased citations

- maximum visibility for your research: over $100 \mathrm{M}$ website views per year

At $\mathrm{BMC}$, research is always in progress.

Learn more biomedcentral.com/submissions 